\title{
O PLANO "PRESTES MAIA" E A IDEOLOGIA DO PLANEJAMENTO URBANO EM CAMPINAS: O PODER E OS LIMITES DAS IDEIAS DE UM URBANISTA
}

\section{Fabíola Rodrigues}

Coordenadoria Setorial do Patrimônio Cultural (CSPC) Secretaria Municipal de Cultura Prefeitura de Campinas

\section{Resumo}

Este texto trata de analisar o contexto de implantação do Plano de Melhoramentos Urbanos de Campinas, também conhecido como Plano Prestes Maia, entre as décadas de 1930 e 1960. Idealizado e parcialmente executado pelo afamado engenheiro-urbanista Francisco Prestes Maia, o Plano de Melhoramentos Urbanos mudou profundamente as feições urbanas da cidade de Campinas, imprimindo no imaginário social e político da cidade certa concepção de planejamento urbano associada à racionalidade, ao progresso e à modernidade, marcas então tomadas como incontesti da pujança econômica e do papel de destaque que a cidade assumiria no cenário da economia paulista.

Palavras-chave: Planejamento Urbano; Urbanização; Política Urbana

\section{Abstract}

This paper aims to analyze the implementation context of the Campinas Master Plan also known as "Prestes Maia Plan". Designed and partially implemented by the renowned engineer Prestes Maia, the Master Plan has deeply changed the urban features in the city of Campinas, printing in social and political imaginary of the city a certain conception of urban planning associated with rationality, progress and modernity, brands seen as incontesti of the economic importance and the important role that the city would take in the context of São Paulo State economy. Keywords: City planning; Urbanization; Urban Policy 
O Plano de Melhoramentos Urbanos de Campinas, datado de 1938, é o primeiro plano de ordenamento urbano da cidade de Campinas de longo prazo, e foi precisamente aquele de maior duração: sua implantação se estendeu do final dos anos 1930 até o final dos anos 1960, e sua "aposentadoria" só se realizou com a emergência do Plano Diretor de Desenvolvimento Integrado (PDDI), de 1971.

Ao Plano de Melhoramentos Urbanos de Campinas se associam alguns grandes marcos urbanos existentes na cidade até hoje: a caixa d'água em formato de mirante, denominada "Torre do Castelo", o prédio do Fórum Municipal, o prédio dos Correios, o alargamento das então acanhadas avenidas Campos Sales e Francisco Glicério, sendo que a esta última se associa, ainda, o grande trauma da condição de "moderna" cidade que o plano conferiu a Campinas, que foi, precisamente, a demolição da antiga Igreja do Rosário, e a conseqüente remodelação do Largo do Rosário.

É indubitável que o Plano de Melhoramentos Urbanos fez história no planejamento urbano de Campinas, e o que é mais fascinante em tudo isso é que esse importante plano é mais conhecido por sua alcunha, que o liga diretamente ao engenheiro-urbanista Francisco Prestes Mais, o idealizador do Plano de Melhoramentos Urbanos, contratado pela Prefeitura de Campinas, em 1934, para a confecção de um plano de ordenamento e renovação urbanos que apagasse da cidade suas modestas feições coloniais e lhe imprimisse ares de cidade rica e moderna (RIBEIRO, 2007; RODRIGUES, 2008).

Nesse sentido, a longa duração do Plano de Melhoramentos Urbanos (ou simplesmente Plano Prestes Maia) e sua persistente associação com o engenheiro urbanista que o idealizou e que parcialmente coordenou sua execução - o que não veio a se repetir depois em nenhum momento da história da cidade - nos incitam à investigação das razões técnicas e políticas que tornaram Prestes Maia o "pai", o ícone e a eterna referência reverenciada do planejamento urbano em Campinas.

No contxto dos anos 1930, a velha malha desgastada do centro urbano, permeada de rugosidades que se formaram na superposição de espaços-tempo econômicos e sociais distintos e que engrendram um desenho urbano assimétrico, retalhado, invadido de reentrâncias, não mais interessava ao poder local, que clamava por intervenções no desenho urbano da cidade que melhor exprimissem a condição de centro industrial dinâmico em ascensão que Campinas representava naquele tempo. 
A racionalização do sistema viário e a renovação urbana do centro da cidade não apenas dotavam Campinas de feições mais adequadas à sua pujança econômica e à sua importância na economia paulista, mas fundamentalmente se configurava como desejada estratégia de valorização imobiliária, que permitiria ampliar os lucros auferidos sobre uma terra urbanizada e já ocupada, favorecendo antigos estratos da elite local, cuja riqueza havia se deslocado, após a crise de 1929, do setor cafeeiro para o setor mercantil-imobiliário (SEMEGHINI, 1991; RODRIGUES, 2008).

Do mesmo modo, a demanda pela incorporação de áreas mais baratas, ainda não urbanizadas e que respondessem às necessidades habitacionais de um crescente operariado, interessava deveras ao capital industrial, cujos custos de reprodução se encontravam fortemente associados ao custo locacional da moradia operária.

Aliás, deve-se mencionar que ao capital oriundo do complexo cafeeiro interessavam, sobremaneira, os incentivos à moradia popular. Isto porque, de um lado, o mercado imobiliário se configurava como uma oportunidade de diversificação de investimentos, e de outro lado, porque a elevação da oferta de moradias, especialmente em regiões mais distantes do centro, próximas das plantas industriais, reduziria os custos de manutenção da força de trabalho, ampliando os lucros auferidos pelo capital.

Com efeito, os clamores de engenheiros e técnicos da Repartição de Obras e Viação (ROV), da Prefeitura de Campinas, de empresários, industriais e de loteadores são atendidos em 1934, quando o Poder Executivo contrata o engenheiro-urbanista Francisco Prestes Maia, encarregado de elaborar o Plano de Melhoramentos Urbanos de Campinas, e quando cria, na seqüência, a Comissão de Melhoramentos Urbanos. ${ }^{1}$

A contratação do Plano de Melhoramentos Urbanos ao engenheiro Prestes Maia vem responder, portanto, aos anseios do poder econômico e político local, especialmente aqueles setores ligados à indústria, à atividade imobiliária e, posteriormente, ao setor de transportes, que viam na ampliação da malha urbana e na redinamização imobiliária do centro da cidade oportunidades valiosas (e que

\footnotetext{
${ }^{1}$ A Comissão de Melhoramentos Urbanos foi criada pela Lei no 490, de 1936, pelo então prefeito João Alves dos Santos. A comissão inicialmente constituída pelo Prefeito João Alves dos Santos, compôs-se pelos seguintes membros: Azael Álvares Lobo, Edmundo Barreto, José Alves T. Nogueira, Arthur Canguçu, Euclydes Vieira, Mario Penteado, todos nomeados pela prefeitura. (apud RIBEIRO, 2007, p. 46).
} 
efetivamente se confirmaram) de negócios altamente rentáveis.

As pressões no sentido da contratação de um plano urbanístico que atendesse no médio e no longo prazo especialmente aos interesses desses três setores - industrial, imobiliário e de transportes - se fizeram presentes, efetivamente, desde o início da década de 1930.

Nesse sentido, na introdução do "Rascunho de Exposição Preliminar", súmula dos objetivos e diretrizes que norteariam a elaboração do Plano de Melhoramentos Urbanos de Campinas, Prestes Maia chama a atenção para a importância cívica do planejamento urbano:

[...] na antiguidade a fundação de uma cidade era uma solenidade religiosa [...] hoje, o inicio de estudos urbanísticos deve ser considerado uma solenidade cívica, por marcar o inicio da vida urbana consciente e organizada (RASCUNHO DE EXPOSIÇÃO PRELIMINAR, 1935, p.81).

Nesse excerto, em que Prestes Maia enfatiza o valor cívico dos estudos urbanísticos, reputando-Ihes o poder de organizar de modo racional e consciente a vida urbana, fica bastante evidente que a racionalização da circulação viária e a modernização do desenho urbano eram questões de fundamental importância para os agentes diretamente envolvidos na contratação de Prestes Maia.

Ou seja, o próprio corpo de engenheiros e técnicos da Repartição de Obras e Viação - direta e indiretamente envolvidos no movimento de expansão imobiliária da cidade, mas também empresários, advogados e loteadores que compunham a Comissão de Melhoramentos Urbanos e que representavam esses e outros interesses das camadas ricas da população de Campinas.

O Plano de Melhoramentos Urbanos pretendia para Campinas grandes e largas avenidas, de trânsito rápido, que permitiriam a interligação dos nascentes bairros dos arrabaldes com o centro urbano; a implantação de modernos edifícios públicos, a disciplina do uso e ocupação do solo - por meio do "zoning" - e, em última instância, a otimização dos custos de (re)produção do capital.

O investimento na realização de um plano urbanístico dessa envergadura, que Prestes Maia idealizou se implantar num período de 20 a 50 anos, e que efetivamente pautou a agenda da política urbana em Campinas durante quase 40 anos, exigia um amplo convencimento do poder econômico e político local da sua necessidade.

Isso porque as vultosas desapropriações e as obras de ampliação e reordenação do sistema viário - evidentemente muito requeridas pelos setores 
imobiliário e de transportes - atravessavam gestões e consumiam parcelas significativas do orçamento público e dos recursos humanos da Prefeitura, especialmente da ROV (Repartição de Obras e Viação).

Exatamente porque a implantação do plano urbanístico proposto por Prestes Maia seria morosa e dispendiosa, foi inegável o surgimento de símbolos que ratificassem seu valor econômico e estético, perdurando na memória social da cidade as representações de modernidade, progresso e eficiência a partir das quais Campinas queria se ver (re)conhecida.

No tocante a esse aspecto, como muito apropriadamente lembra Ribeiro (2007), a construção da Torre do Castelo, reservatório elevado de água do Jardim Chapadão, foi, ao mesmo tempo, símbolo da eficiência e da modernização dos serviços públicos ${ }^{2}$ e marco da monumentalidade do novo desenho urbano desejada pelo Plano de Prestes Maia.

Esse "templete", sugerido pelo próprio Prestes Maia no Plano de Melhoramentos Urbanos, também comportava a função de mirante, permitindo ao observador vislumbrar todo o traçado viário proposto pelo engenheiro em seu plano urbanístico, conforme mostra muito apropriadamente a figura reproduzida abaixo.

${ }^{2}$ O reservatório do Chapadão foi projetado para abastecer toda a região mais alta do município, a zona norte, que enfrentava graves problemas de abastecimento (RIBEIRO, 2007). 


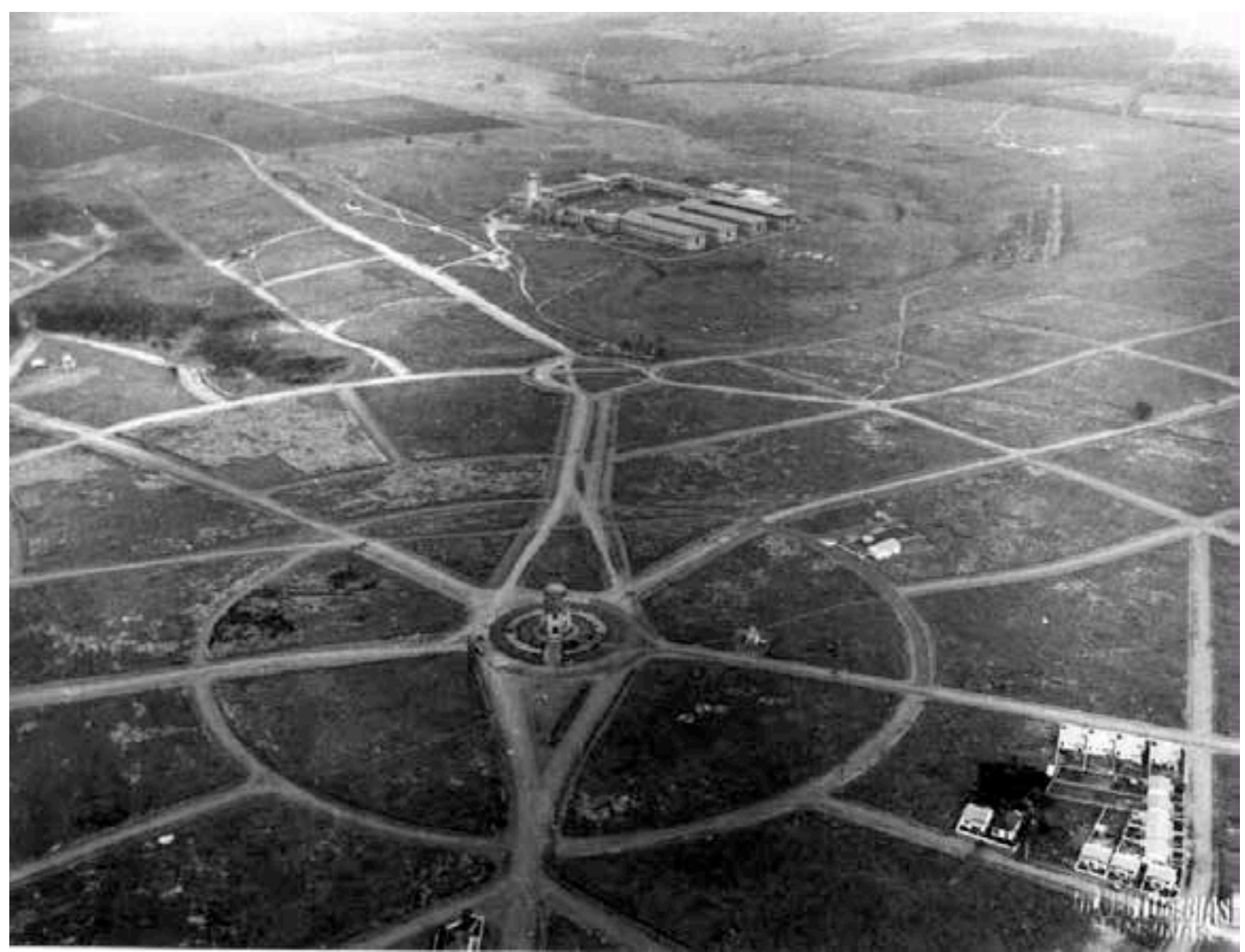

Figura 1: Década de 1940. Vista aérea do Jardim Chapadão, vendo-se ao centro a Torre do Castelo e ao seu redor as diretrizes viárias propostas pelo Plano de Melhoramentos Urbanos.

Fonte: Acervo da Biblioteca Municipal de Campinas

O Jardim Chapadão e seu "templete" na praça central - a Torre do Castelo são exemplares da forte relação estabelecida entre o capital imobiliário e o Poder Público, através dos melhoramentos urbanos previstos no Plano de Prestes Maia, e que favoreciam os interesses desses agentes privados.

O caso da antiga Fazenda Chapadão, de propriedade de Otaviano Alves de Lima, é realmente muito emblemático: velha fazenda cafeeira, essa gleba foi retalhada e transformada no loteamento Jardim Chapadão. A abertura desse empreendimento, autorizado pelo Poder Público Municipal, através da Resolução no 977, de 1937, evidencia a conversão do capital agrário em capital imobiliário, na distensão do complexo cafeeiro; momento em que a cafeicultura nas terras já cansadas do Leste Paulista perde em rentabilidade para a atividade industrial e, mormente, para a atividade imobiliária.

Ao mesmo tempo, a rentabilidade dessas antigas áreas ocupadas pelo café e agora convertidas em áreas urbanas só é possível mediante o explícito apoio do Poder Público que viabiliza, efetivamente, através de incentivos financeiros diversos, essa inversão de capitais. 
Nesse sentido, estabelece a Resolução no 977:

Approva projecto de arruamento e divisão em lotes de terrenos da Fazenda Chapadão: A Câmara Municipal de Campinas resolve:

Art. 10 - Fica approvado o projecto de arruamento e divisão em lotes, de terrenos da Fazenda Chapadão, de propriedade de Otaviano Alves de Lima, com observações e restrições apresentadas pela D.O.V. ${ }^{3}$

Art. $2^{\circ}$ - Não será permittida nenhuma construção nova antes da execução da terraplenagem das ruas projectadas.

Art. 30 - Fica concedida isenção de impostos municipaes pelo prazo de 5 (cinco) annos para os lotes não vendidos.

Art. 40 - Revogam-se as disposições em contrário.

Mando, portanto, todas as autoridades a quem o conhecimento e execução da presente resolução competir, que a cumpram e a façam cumprir tão inteiramente como nella se contem"

Campinas, 31 de março de 1937

João Alves dos Santos

Prefeito Municipal (LEIS, RESOLUÇÕES E ACTOS DIVERSOS PROMULGADOS NO EXERCÍCIO DE 1937).

${ }^{3}$ D.O.V - Diretoria de Obras e Viação 


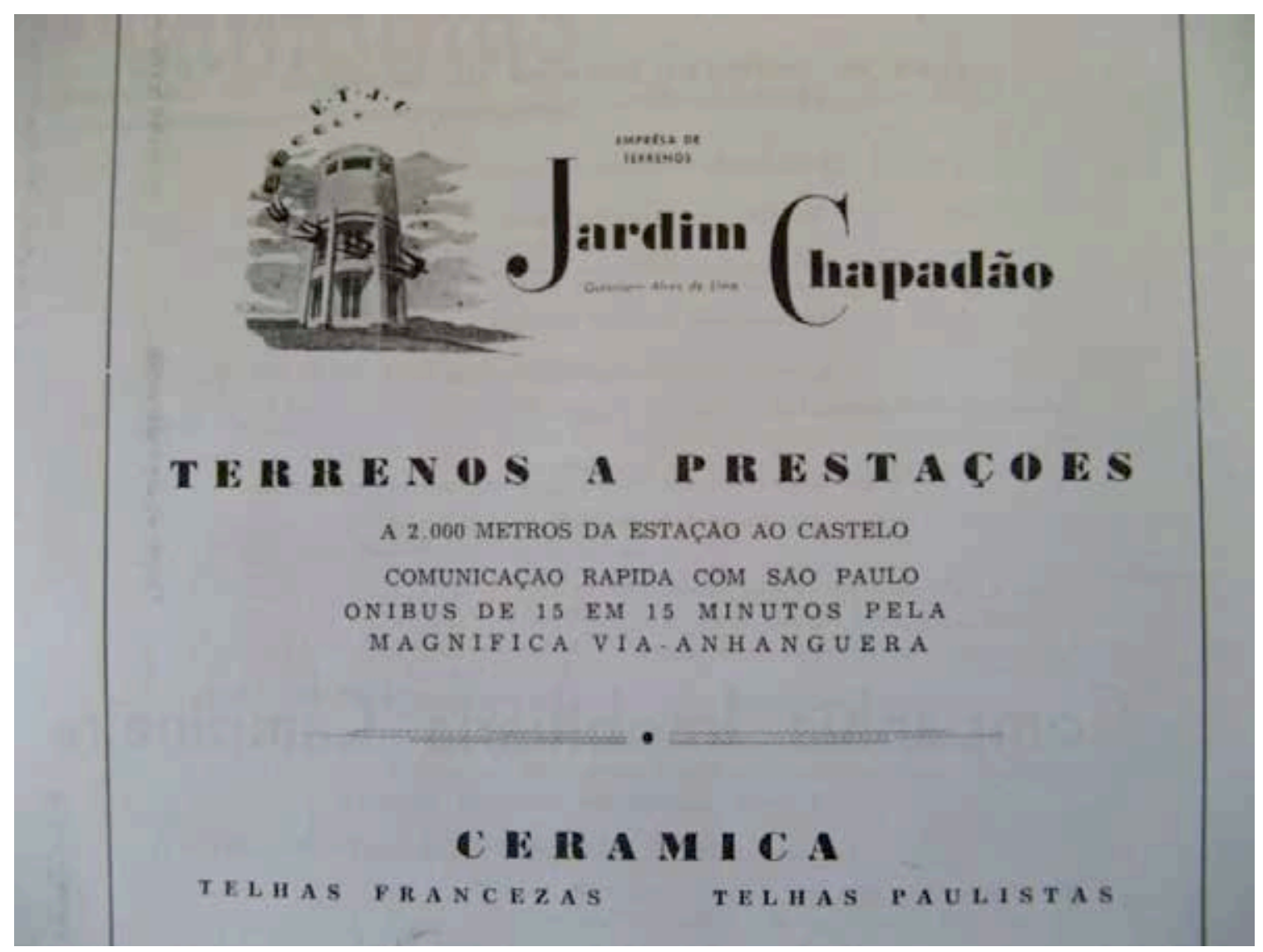

Figura 2: Década de 1940. Propaganda da Emprêza de Terrenos "Jardim Chapadão". Fonte: Arquivo da Câmara Municipal de Campinas.

Como bem o mostra a Resolução no 977, de 1937, promulgada pelo prefeito João Alves dos Santos, além da aprovação de novos loteamentos em áreas distantes da zona urbana efetivamente ocupada, (o que favorecia os interesses desse novo capital imobiliário, a quem interessava a incorporação de glebas mais distantes, invariavelmente antigas propriedades cafeeiras, espólios de família que estavam em seu poder), a Prefeitura ainda concedia isenção de impostos, ao proprietário, para os lotes não vendidos.

Essa medida, é evidente, minimizava enormemente os riscos do empreendimento, de modo que o capital loteador poderia lançar, simultaneamente, vários loteamentos esparsos pela cidade.

A atividade loteadora em Campinas, em fins dos anos quarenta [...] superou em muito tudo o que havia sido feito até então. [...] Os novos loteamentos concentraram-se [...] afastados do núcleo urbanizado [...] onde a terra era barata .... (SEMEGHINI, 1991, p. 126).

De fato, a atividade imobiliária e o movimento da construção civil atingem uma magnitude até então inimaginável a partir dos anos 1940.

Nesse período, inúmeros novos loteamentos e principalmente núcleos de 
moradia popular são autorizados e implantados na cidade, tanto como estratégia de revalorização imobiliária do centro (a partir da expulsão dos pobres e de suas moradias precárias - os cortiços - dessa região), quanto como estratégia de ampliação dos lucros do capital imobiliário.

Aliás, deve-se mencionar a forte complementaridade entre essas duas estratégias, uma vez que o capital imobiliário encontrava um público cativo entre os trabalhadores "expulsos" para as novas vilas que Ihes eram construídas nos arrabaldes, configurando-se um mecanismo de rebaixamento de custos do capital industrial.

Por sua vez, o capital industrial contava com a facilidade da localização de núcleos habitacionais operários próximos das plantas industriais, o que reduzia os custos com transportes, muito embora elevassem os custos de deslocamento para os trabalhadores na direção da economia de comércio e serviços, ou seja, o centro da cidade.

No entanto, esse duplo movimento de renovação imobiliária do centro e de produção de novos espaços de moradia, especialmente para as camadas populares, nos arrabaldes do perímetro urbano, não se fez sem conflitos e não pôde prescindir de forte intervenção do Poder Público.

O excerto reproduzido abaixo, constante do Relatório Municipal de 1938, referente a um projeto de habitação popular que o município submetera à chancela do governo federal, explicita essa tensão entre a presença das camadas populares no centro da cidade e o projeto de renovação urbana capitaneado pelo Poder Público, através da contratação do Plano de Melhoramentos Urbanos:

\footnotetext{
A Prefeitura aguarda [...] a aprovação pela Secretaria da E. e S. Pública de uma legislação que propoz para habitações operarias de tipo minimo e para construções operarias economicas. Aprovada a legislação e posta em practica, tera a Prefeitura resolvido um problema de grande alcance social, podendo então iniciar com energia o saneamento dos cortiços que proliferam pela cidade, abrigando cerca de 1.000 familias com uma população superior a 4.000 pessoas, em condições de higiene que se pode aquilatar pelas seguintes medias obtidas em 46 cortiços: W.C, 1 para cada 6 famílias; chuveiros, 1 para cada 10 famílias; pias, 1 para cada 20 famílias; tanques, 1 para cada 3,5 famílias; fogões, 1 para cada 3 famílias. Com todas essas deficiências, ás quais se deve acrescentar o péssimo estado de conservação dos predios e o completo desacordo com o Código de Construções, o locativo medio dos prédios é de $47 \$ 000$. Esse locativo permite a construção de habitações higiênicas, todas dotadas de instalações sanitárias, chuveiros, pias e tanques, sem a atual promiscuidade, desde que as autoridades estadoaes aprovem a nova legislação sugerida por esta Prefeitura e baseada, aliás, no que vem sendo posto em practica há alguns anos no Distrito Federal" (RELATÓRIO MUNICIPAL DE 1938, p.61).
} 
O interesse suscitado por esse excerto reside também no retrato que ele permite compor das condições de vida experimentadas pela população pobre em Campinas, ainda na década de 1930, quando somente se principiava um movimento mais consistente de urbanização da população, o que problematiza a velha cantilena tantas vezes evocada pelos gestores públicos de que a falência da atuação das políticas públicas na cidade deveu-se ao forte fluxo migratório que acorreu para o município, sobremaneira nos anos 1970.

Na verdade, mais uma vez, o que essa rica documentação produzida pelo próprio Poder Público mostra é que os custos sociais exigidos para a realização de um ambicioso projeto de modernização urbana, possível graças a significativos investimentos públicos, (mas que na sua realização consagrou a reboque o interesse de certos grupos específicos, mormente do trinômio capital industrial, imobiliário e de transportes) foram excessivamente altos e muito desigualmente pagos, já que os maiores ônus recaíram sobre a população menos favorecida, empurrada para os arrabaldes da cidade.

Exemplar do poder do capital imobiliário de induzir a produção de uma nova estrutura urbana em Campinas, nesse período, visando sempre a otimização das condições de sua reprodução, é a formação da Vila Itapura, na região do bairro Guanabara, de propriedade da Companhia Rossi \& Borghi, nos termos do DecretoLei no 94/1941, que autoriza a implantação de habitações populares nas imediações de áreas industriais.

A Vila Itapura, compreendida pelos arruamentos "Prefeito Passos", "Visconde de Taunay", "Barata Ribeiro", "Tiradentes", "Barão de Atibaia", "Álvaro Muller", "Coelho Neto" e "Engenheiro Saturnino de Brito" se localizava nas imediações da Fábrica de Tecidos Elásticos Godoy e Valbert (1921), Fábrica de Chapéus Cury (1923) e Companhia Campineira de Óleo (19_), promovendo uma ocupação residencial em uma área nitidamente industrial.

Essa implantação, representativa das inúmeras vilas operárias edificadas em Campinas na década de 1940, cujo objetivo era responder à demanda habitacional das camadas populares, implicava, contudo, ônus significativos para essa população, que era "condenada" a conviver com o barulho e a poluição das fábricas. (RIBEIRO, 2007).

Ainda nesse contexto, no que diz respeito, especificamente, ao movimento da construção civil, enquanto indicador da atividade imobiliária, o quadro abaixo 
apresenta algumas informações bastante interessantes acerca da mudança no seu perfil entre o final dos anos 1930 e o início da década de 1940.

De fato, vê-se que entre 1937 e 1943, em Campinas, edificou-se uma área total de 322.990,72 m2, com nítido predomínio das construções residenciais, que totalizaram, no período, 251.397, $75 \mathrm{~m} 2$, seguidas pelas construções industriais $(39.977,66 \mathrm{~m} 2)$ e pelas construções comerciais $(31.915,31 \mathrm{~m} 2)$.

Contudo, ao se observar os totais edificados por ano, ver-se-á que o ano de 1937 apresenta o volume mais elevado de área edificada (53.943,00 m2), seguido pelo ano de 1940 (52.048,96 m2); porém, a despeito da proximidade do total da área edificada para 1937 e 1940, é possível identificar uma sutil mudança qualitativa: enquanto em 1937 predominavam as construções residenciais (33.775,00 m2), seguidas pelas construções industriais $(18.973,00 \mathrm{~m} 2)$, em 1940, como nos demais anos da década (com exceção de 1941), à predominância das construções residenciais $(43.175,10 \mathrm{~m} 2)$, seguem-se as construções comerciais $(7.231,86 \mathrm{~m} 2)$, o que parece ser um indicativo importante da renovação urbana que o centro de Campinas começava a experimentar, já que houve um incremento na área comercial edificada nos primeiros anos de 1940, quando comparado com os últimos anos da década de 1930.

Nesse sentido, muito apropriadamente Carpintero (1996) observa:

Com a derrocada do café, desapareceram os elementos de sua comercialização, as casas comissárias e os exportadores. [...] Com o crescimento da população e a industrialização havia, entretanto, crescido o comércio de consumo imediato. A Rua 13 de Maio se tornara o centro comercial por excelência da cidade... ( p. 61).

Quadro 1: Evolução da Área Construída (m2) Campinas

1937-1943

\begin{tabular}{||lllll||}
\hline Area Construída $(\mathrm{m} 2)$ & & & \\
\hline Ano & Residencial & Comercial & Industrial & Total \\
\hline 1943 & $34.937,16$ & $5.715,30$ & $5.246,70$ & $45.899,16$ \\
1942 & $31.281,87$ & $3.486,81$ & $2.851,20$ & $37.619,88$ \\
1941 & $39.941,88$ & $1.612,78$ & $3.907,76$ & $45.462,42$ \\
1940 & $43.175,10$ & $7.231,86$ & $1.642,00$ & $52.048,96$ \\
1939 & $36.490,74$ & $8.169,56$ & $1.139,00$ & $45.799,30$ \\
1938 & $31.796,00$ & $4.504,00$ & $5.918,00$ & $42.218,00$ \\
1937 & $33.775,00$ & $1.195,00$ & $18.973,00$ & $53.943,00$ \\
\hline Total & $251.397,75$ & $31.915,31$ & $39.677,66$ & $322.990,72$ \\
\hline
\end{tabular}

Fonte: Apud Relatório Municipal de 1943, p. 136.

A Tabela 1, reproduzida abaixo, informa a respeito da evolução do total de novas construções e reformas no período 1924-1950. Novamente se percebe que há um forte incremento no mercado imobiliário e da construção civil nesses anos, 
em especial durante os anos 1940/50, quando são construídas 6.276 novas edificações e são reformados 2.187 imóveis.

Efetivamente, ao se comparar o total de novas edificações e de reformas entre os períodos 1924/1930 e 1940/1950 vê-se que o volume de novos edifícios cresce cerca de $150 \%$ no último período (1940/1950), com relação ao primeiro período (1924/1930), enquanto que o volume de reformas cresce aproximadamente $93,9 \%$ na comparação do primeiro com o segundo período.

Somente entre 1931/1940 e 1940/1950 o incremento no volume de novos prédios foi da ordem de $99,2 \%$ e a ampliação no total de reformas foi de 24,12\%, o que vem reforçar a percepção de que o município de Campinas experimentava um novo padrão de urbanização a partir dos anos 1940.

[...] o período 1947/1952 assinala uma importante mudança de escala no que se refere à atividade imobiliária na cidade. Mas a mudança não foi apenas qualitativa: ao contrário, nesse período configurou-se um novo padrão de crescimento urbano - o mesmo, em linhas gerais que caracteriza outras grandes cidades brasileiras (SEMEGHINI, 1991, p.p. 126-7).

Tabela 1: Comparativo do Movimento da Construção Civil Campinas -1924-1950

\begin{tabular}{lcc} 
Período & Novos & $\begin{array}{c}\text { Prédios } \\
\text { Reformas }\end{array}$ \\
\hline $1924-1930$ & 2.509 & 1.128 \\
$1931-1940$ & 3.151 & 1.762 \\
$1940-1950$ & 6.276 & 2.187 \\
\hline
\end{tabular}

Elaborado a partir do Relatório Municipal de 1943, p. 137 e Relatório Municipal de 1949

É importante mencionar que esse substantivo crescimento imobiliário observado em Campinas entre os anos 1930-1950, em especial a partir da década de 1940 se fez amparado também pelo forte crescimento da atividade industrial e pelo incremento demográfico, uma vez que a área urbana do município principia a absorver contingentes cada vez mais importantes de trabalhadores em funções tipicamente urbanas.

Entre 1930 e 1940, as atividades urbanas em Campinas já eram mais relevantes que as rurais. Em $1940,60,4 \%$ da população economicamente ativa (PEA) estava inserida em atividades urbanas - $20,2 \%$ no setor secundário e $40,2 \%$ no terciário - cabendo ao setor primário $39,6 \%$ da PEA (BAENINGER, 1996, p. 41). 
Tabela 2: Prédios Existentes na Cidade de Acordo com a Idade do Imóvel - Município de Campinas, 1949

\begin{tabular}{lll} 
Idade & No prédios & Distribuição Relativa \\
mais de 40 anos & 5.456 & 30,20 \\
$40-35$ anos & 920 & 5,09 \\
$35-30$ anos & 849 & 4,70 \\
$30-25$ anos & 749 & 4,15 \\
$25-20$ anos & 1.800 & 9,96 \\
$20-15$ anos & 1.754 & 9,71 \\
$15-10$ anos & 1.456 & 8,06 \\
$10-05$ anos & 1.464 & 8,10 \\
menos de 05 anos & 3.617 & 20,02 \\
Total & $\underline{18.065}$ & $\underline{100,00}$ \\
\hline
\end{tabular}

Fonte: Elaborado a partir do Relatório Municipal de 1949

Essa irracional e ostensiva expansão urbana se fez com a anuência de sucessivas gestões, que permitiram ao capital imobiliário usufruir do lucro máximo no parcelamento do solo urbano, o que produziu uma malha urbana assistemática, ponteada de vazios urbanos à espera de valorização, com difícil interligação (SEMEGHINI, 1991), o que penalizou a população mais pobre, obrigada a realizar múltiplos e dispendiosos deslocamentos para transitar do local de trabalho até o local de residência.

Sem dúvida alguma a década de 1950 é alegórica da radicalidade da intervenção urbana proposta pelo Plano de Melhoramentos Urbanos, visto que foi exatamente nesse momento que a velha malha do centro da cidade foi rasgada em grandes avenidas, viadutos, seu traçado retificado e suas praças remodeladas.

É curioso que esse frenesi de novas obras se tenha realizado exatamente no limite da "validade" do Plano de Prestes Maia, que fôra estimado, pelo próprio engenheiro, como uma empreitada para um período de 20-50 anos.

Contudo, o Plano Prestes Maia perdera muito de sua vida útil em decorrência da expansão urbana desmesurada, que engendrou uma malha urbana perfurada por áreas vazias, dificultando a interligação entre as regiões efetivamente ocupadas, de modo que nem mesmo uma criteriosa hierarquização do sistema viário seria capaz de solucionar os graves problemas de deslocamento que a cidade já enfrentava.

Concomitantemente, o ambicioso projeto do poder econômico e político local de modernização e de racionalização da malha urbana, especialmente do centro da cidade, em consonância com o que se fazia de mais vanguardista nos EUA e na 
Europa, como sugere o próprio Prestes $\mathrm{Maia}^{4}$, vê-se corroído pelas crescentes restrições orçamentárias, resultado da diminuição de recursos repassados pelo Governo Estadual, mas também pelo aumento extraordinário das despesas com obras de infraestrutura e de serviços urbanos, nas áreas cada vez mais longevas loteadas pelo capital imobiliário.

O ofício encaminhado pelo então Prefeito Municipal Dr. Antônio Mendonça de Barros à Câmara Municipal, em 1954, é revelador das dificuldades financeiras enfrentadas pelo município naquele momento:

Pelos documentos apresentados, verificará a Ilustrada Câmara que o ano de 1954 foi um dos mais difíceis da atual administração porque tivemos de enfrentar a alta assustadora de todos os preços e salários, a ausência de matéria-prima do mercado e a quase impossibilidade de conseguirmos materiais de importação [...]. Por último, a grave crise econômica do Estado atingiu diretamente Campinas, impedindo a realização de diversas obras e serviços prometidos pelo Governo Estadual..." (RELATÓRIO MUNICIPAL DE 1954$)^{5}$

Contudo, paradoxalmente, os gastos mais substantivos com a implantação do Plano de Melhoramentos Urbanos datam desse período, quando, mais uma vez, os interesses privados se superpõem à lógica de parcimônia e justiça no equacionamento do gasto público (ZIMMERMANN, 1989).

Isso significa dizer que a morfologia do centro de Campinas foi radicalmente alterada, sobremaneira entre a segunda metade dos anos cinquenta e o início dos anos 1960, atendendo, novamente, aos interesses do capital imobiliário (que pressionava pela revalorização do centro, possível graças à elevação do preço dos imóveis e pela própria verticalização, ambas oportunizadas pelas mudanças que o plano produziu) e aos interesses do capital do setor de transportes, que foi agraciado com a ampliação e hierarquização do sistema viário, o que terminou por chancelar o uso do ônibus e do automóvel como formas preferenciais de deslocamento entre o centro e as demais regiões da cidade.

No que tange a esse aspecto, como bem postulou Semeghini (1991):

Finalmente, uma conseqüência marcante desse padrão de crescimento foi a mudança nas feições da cidade. Essa mudança se traduz fisicamente nos novos arranha-céus, avenidas e logradouros, por um lado, e no surgimento dos novos (e distantes) bairros e loteamentos populares. Socialmente, ela implicou numa crescente segregação espacial dos

\footnotetext{
4 Vide o texto "Rascunhos de Exposição Preliminar" (1935), publicado no "Relatório Municipal de 1936" e o Ato n¹18/1938, "Plano de Melhoramentos Urbanos".

${ }^{5}$ Ofício de encaminhamento do Relatório Municipal do Exercício de 1954, enviado pelo Prefeito Dr. Antônio Mendonça de Barros à Câmara Municipal.
} 
trabalhadores e das camadas de mais baixas rendas. Até os anos cinqüenta, era comum a existência numa mesma área urbana de residências (e habitantes) de distintos níveis sociais e de rendas, embora, é claro, já existissem bairros mais nobres. A valorização intensa e especulativa desses terrenos expulsa dessas áreas a população pobre, que juntamente com o crescente contingente migratório passou a deslocar-se para as áreas mais distantes. Ao mesmo tempo, as áreas mais centrais vão sendo recicladas, com o impulso à verticalização (p. 128, grifos do autor).

É mesmo muito interessante observar o tratamento que o Poder Público, na implantação do plano urbanístico proposto por Prestes Maia, deu, de forma mais ampla, à questão do uso e ocupação do solo, e mais especificamente à questão do zoneamento residencial.

Muito embora Prestes Maia não tenha dispendido muito tempo e esforço no detalhamento do zoneamento residencial (sua ênfase recaía na necessidade do zoneamento, per se, o que significa dizer, da disjunção no uso do solo em zonas específicas, com legislação própria e diferenciada) há uma pequena menção à forma como o engenheiro-urbanista idealizava a formação das zonas residenciais:

Em exposições anteriores insisti sobre a concepção nova que é a unidade residencial ("neigh-bourhood = unit). Assim denominam-se porções da cidade que, ao menos para as actividades do bairro, funcionam como unidades "self-sustaining" ou completas. Enchem o vão da grande malha formado pelo reticulado de radiaes e perimetraes [...] [e] podem assemelhar-se a jardins invertidos.

A differença consiste em terem zona residencial no centro e commercial no perimetro, ao passo que nas cidades-jardins verifica-se 0 inverso" (RASCUNHO DE EXPOSIÇÃO PRELIMINAR, 1935, p.p. 82-3).

Fica claro, aqui, que a implantação do Plano de Melhoramentos Urbanos não se fez necessariamente de forma fidedigna às diretrizes propostas por Prestes Maia, mas ao contrário, essas diretrizes foram "interpretadas" segundo os interesses que o Poder Executivo local encampou ao longo de toda a sua implantação, já que a formação dos novos bairros não seguiu, rigorosamente, o conceito de policentralidades proposto por Prestes Maia.

De todo modo, há outra passagem do "Rascunho de Exposição Preliminar" (1935) em que Prestes Maia deixa entrever, mais especificamente, sua concepção acerca da localização espacial das camadas trabalhadoras.

Esta concepção "segregadora" foi, contudo, intensamente incorporada na atuação do capital imobiliário e na execução das políticas públicas:

Bairros Industriaes - O principal será localizado na faixa da Paulista, além do Armazém Regulador - onde serão facilmente servidos pelas três 
Estradas [de ferro] e pela rodovia.

Distam pouco da cidade e, pela situação em relação aos ventos não enviarão sua fumaça sobre a cidade. Distando pouco da Vila Industrial, São Bernardo, etc, o recrutamento da mão-de-obra será fácil... (RASCUNHO DE EXPOSIÇÃO PRELIMINAR, 1935, p. 108).

Os bairros industriais, mais distantes da malha urbana adensada, em posição cujos ventos não trariam incômodo "à cidade" (ou seja, ao centro) deveriam ser aproximados da zona residencial operária, o que facilitaria o "recrutamento" da mão-de-obra, ao mesmo tempo em que criaria uma zona de amortecimento entre a área industrial (suja, barulhenta, incômoda) e a zona central, que seria remodelada de acordo com as diretrizes viárias e de zoneamento constantes do plano urbanístico idealizado por Prestes Maia.

A importância dessa passagem nas reflexões de Prestes Maia sobre o urbanismo em Campinas é virtuosamente heurística, já que historiciza os processos de expulsão da população pobre do centro da cidade e da profunda segregação socioespacial que se delinearam quando da expansão imobiliária desmesurada, na direção de áreas ainda não urbanizadas.

$\mathrm{Na}$ verdade, essa passagem ilumina uma questão central na compreensão do modo como se fez a expansão urbano-industrial em Campinas: contrariamente ao que poderia parecer numa análise mais superficial, a "crise urbana" vivenciada pelo município nas décadas seguintes, não é exatamente produto da "falta" de planejamento urbano, mas sim conseqüência de um modelo de planejamento altamente segregador, que induziu a expulsão da população trabalhadora para áreas contíguas às zonas industriais, que se formaram em pontos cada vez mais distantes do núcleo urbano efetivamente ocupado, dotado de melhor infraestrutura e de serviços urbanos.

Isso significa dizer que os interesses do capital e da população trabalhadora foram muito diferencialmente tratados pelo Poder Público, com nítido favorecimento ao trinômio capital imobiliário, capital industrial e capital do setor de transportes, aos quais, mesmo ao custo de um forte endividamento e da consequente precarização das políticas públicas, o Plano de Melhoramentos Urbanos fartamente favoreceu.

Esse favorecimento - nos anos 1950 especialmente ao capital imobiliário, que se fez durante todo o período de implantação do plano na forma de uma legislação que era protecionista da parte do Poder Público e liberal nas contrapartidas do capital, é absolutamente inegável: de fato, nessa década, o 
crescimento urbano de Campinas se fez em patamares que em muito ultrapassaram os limites do razoável.

Porém, essa acintosa liberdade especulativa do capital imobiliário somente passa se configurar como uma "questão" para o Poder Público quando as exigências do acesso à infraestrutura e aos serviços urbanos por parte da população que habita essas novas franjas da malha urbana se tornam incontornáveis, ao mesmo tempo em que os recursos financeiros minguam nos cofres públicos.

Assim, os primeiros a clamarem por uma regulação mais enérgica da atividade imobiliária são exatamente os engenheiros, arquitetos e técnicos da Diretoria de Obras e Viação, agentes que sofrem diretamente (e ao mesmo tempo) o assédio do capital imobiliário e a pressão da população desassistida, que pleiteia a expansão dos serviços públicos.

O crescimento da cidade está se processando em ritmo acelerado. Foram licenciados durante o ano [1954] 1.788 prédios NOVOS e 689 reformas e aumentos. Por outro lado a expansão da área da cidade atingiu proporções alarmantes: em cerca de 10 anos foram aprovados 436 arruamentos com área total de $70.383 .505,24 \mathrm{~m} 2$ e contendo 115.585 lotes.

Comparando esse total de LOTES com o número dos prédios existentes, que em 31.12.1954 era de

26.179 pode-se avaliar o absurdo que constitue a aprovação desses arruamentos. A revogação parcial da Lei 640 estabeleceu grande confusão para limitação da altura na Zona Central, tornando premente a necessidáde de revisão de toda a legislação urbanística, decretando o NOVO CÓDIGO DE OBRAS e ZONEAMENTO. (RELATÓRIO MUNICIPAL DE 1954 - DEPARTAMENTO DE OBRAS E VIAÇÃO - Grifos do autor).

A seriedade do alerta da Diretoria de Obras e Viação, veiculado no "Relatório Municipal de 1954" estava, realmente, embasada em fatos concretos: a incontrolável expansão imobiliária que se processava em Campinas.

Nesse contexto, a tabela abaixo mostra o elevado número de aprovações de novos arruamentos em Campinas entre 1946 e 1960: nesse período, somados, foram aprovados 498 arruamentos e 142.614 lotes.

Somente no período 1951-1955, de maior movimento de aprovações, foram autorizados 189 arruamentos, correspondente a 37,95\% do total de autorizações expedidas entre 1946-60, e 77.014 lotes, o que equivale a 54\% do total de aprovações do período supramencionado. 
Tabela 3: Arruamentos Aprovados - Campinas -1946-1960

\begin{tabular}{|c|c|c|}
\hline Período & No Lotes & NoArruamentos \\
\hline 1946-1950 & 28.844 & 183 \\
\hline 1951-1955 & 77.014 & 189 \\
\hline $1956-1960$ & 36.756 & 126 \\
\hline
\end{tabular}

Fonte: Elaborado a partir do Relatório Municipal de 1960.

De fato, quando se observam os dados acerca da industrialização em Campinas, na década de 1950, tem-se uma dimensão muito precisa da intensidade da expansão imobiliária, que se fazia atrelada ao pujante desenvolvimento industrial.

Desse modo, é inegável a forte presença da industrialização na conformação demográfica e urbana assumida pela cidade, especialmente a partir dos anos 1950, quando a região de Campinas se consolida como a mais importante área industrial do interior de São Paulo (NEGRI, 1996; BAENINGER, 1996).

De acordo com Seade (1988), em Campinas a

[...] indústria mais importante era a mecânica ( $81,9 \%$ da região) concentrando em 1959 a expressiva cifra de 17,6\% da produção mecânica do Estado, maior inclusive que o peso da indústria mecânica que se localizava na RMSP (excluída a capital)" (p. 93).

A complexidade do desenvolvimento industrial em Campinas a partir dos anos 1950, que carreou uma mudança significativa na composição da sua população, cujo crescimento se fez cada vez mais amparado pelos crescentes saldos migratórios (BAENINGER, 1996), ao mesmo tempo em que reflete e é refletida nas inúmeras mudanças no desenho e nas funções do espaço urbano, engendra demandas econômicas e sociais, oriundas do capital e da força de trabalho, que são muito diferencialmente atendidas.

Acerca desse aspecto, aponta Semeghini (1991),

[...] com a industrialização pesada, mudou o caráter da urbanização em curso. Não se trata agora de um crescimento extensivos da população da cidade, mas de transformações profundas na sua constituição social, produtiva e de padrões de vida. [...] A absorção [da] [...] mão-de-obra em setores modernos, onde é acentuado o peso dos grandes estabelecimentos tanto industriais quanto de comércio e serviços consolidam expressivo contingente de médias e altas rendas, que por sua vez alteram qualitativamente a demanda de serviços pessoais, também diversificandoa e sofisticando-a. (p. 157).

No que se refere propriamente à renovação urbana do centro, que culminou 
na sua valorização imobiliária e, conseqüentemente, numa intensa verticalização, há uma passagem, nesse contexto da implantação mais substantiva do Plano de Melhoramentos Urbanos, que é muito simbólica do significado das transformações urbanísticas então experimentadas pela área central da cidade e pela população ali residente ou que por ali circulava.

Esse episódio é a demolição da Igreja do Rosário, fato marcante no imaginário social da cidade e que mobilizou numa intensidade descomunal os ânimos de diferentes setores da sociedade campineira (CARPINTERO, 1996).

Prevista, textualmente, por Prestes Maia, em seu "Rascunho de Exposição Preliminar", (1935) a demolição da Igreja do Rosário, parte integrante do projeto de remodelação das feições urbanas do centro da cidade, é muito alegórica do que os grupos econômicos e políticos dominantes pretendiam quando da contratação do Plano Prestes Maia: o apagamento radical e inexorável das marcas de uma cidade colonial e das suas formas de sociabilidade difusas, da escala humana da circulação, que deveria ser substituída por uma morfologia moderna, funcional à reprodução do capital, em que predominam os fluxos de alta velocidade (portanto, não humanos) no espaço-tempo das mercadorias, dos veículos automotores, símbolos altivos e incontesti do velho e assaz reiterado ideário da modernidade e do progresso.

Com a desapropriação da Igreja do Rosário [...] resolveu-se de uma vez por todas [...] a questão do alargamento da avenida Francisco Glicério, e da ampliação da nossa principal praça. Firmadas as escrituras respectivas, iniciou-se logo a demolição do templo tradicional [...] A veneração que aquela igreja inspirava não pôde impedir a força incoercível do progresso (CORREIO POPULAR, 28/06/1956, apud CARPINTERO, 1996, p. 65).

Realmente, a demolição da Igreja do Rosário era parte do programa para o alargamento da então rua Francisco Glicério (que alcançaria o estatuto de avenida e de principal artéria do sistema viário do centro da cidade), para a remodelação da Praça Visconde de Indaiatuba (Largo do Rosário), que ganharia a "função" de praça cívica, e para a reorganização dos principais prédios públicos ali existentes, todos acanhadamente de "costas" para o "desenvolvimento", nos termos de Prestes Maia.

É muito emblemático que Prestes Maia insistisse na idéia de que os principais imóveis do centro da cidade, símbolos altaneiros de uma Campinas do passado estivessem de costas para a monumentalidade pretendida por sua intervenção: efetivamente, esses prédios estavam de costas para a Av. Campos 
Sales; eles estavam voltados para a rua Conceição, a "Formosa", projetada para que o passante pudesse apreciar a grandiosidade da "Matriz Nova", o rico edifício em taipa de pilão edificado na segunda metade do XIX.

Nesse sentido, as proposições de Prestes Maia acerca da inversão na composição dos principais edifícios públicos e da demolição da Igreja do Rosário chocaram seus contemporâneos (como ele mesmo previu), exatamente porque elas pretendiam substituir o antigo centro e suas práticas imemorialmente consolidadas por novas formas de deslocamento e de interação; de lugar de encontro e de exibição pública, o centro passa a lugar perfeitamente projetado para a passagem.

\begin{abstract}
A solução ideal para a Praça Indaiatuba consiste em amplial-a, demolir a Igreja, colocar um edifício publico em uma face.

Este seria na rua Regente Feijó, onde existem uns prédios pouco importantes, ou na própria área da praça actual, o que inverteria a praça. Uma solução intermedia, mais barata, seria collocar o edifício principal na praça e um segundo no local apontado da rua Feijó. O edifício principal por sua vez poderia ocupar quer a área do quarteirão da Igreja, quer o da atual praça, realizando a dita

inversão.

Essa inversão seria lógica para combinar com a avenida Campos Salles, caso essa fosse adoptada. Evitaria que a rua de acesso principal chegasse à praça principal da cidade pelos fundos como hoje curiosamente sucede relativamente a diversos edifícios ( $p$. ex. Theatro, Cathedral, Igreja da Praça Indaiatuba). Essas transformações chocam á primeira vista, mas são lógicas (RASCUNHOS DE EXPOSIÇÃO PRELIMINAR, 1935, p.p. 99-100).
\end{abstract}

No Relatório de 1956 - ano da demolição da Igreja do Rosário - o diretor da Secretaria de Obras e Serviços Públicos substitui o tom cauteloso (e de certa forma condenatório), do Relatório de 1954, por um texto efusivo das inovações promovidas pela implantação da fase mais radical do Plano de Melhoramentos Urbanos, que incluía desapropriações, demolições, remodelações e retificações do traçado viário.

Urgia fazer caminhar, em ritmo acelerado, o plano de urbanismo, traçado pelo ilustre engenheiro Prestes Maia, a fim de que, principalmente, a parte central da cidade, servida por ruas estreitas e acanhadas, se ampliasse em benefício de um movimento, cada vez mais crescente, de pedestres e veículos.

Assim é que foram demolidos em 1956, 66 prédios e mais o da Igreja do Rosário, para dar lugar ao alargamento das ruas.

O número maior de demolições se registrou na Rua Campos Sales, com 31 edificações postas abaixo, [...] e na Rua Francisco Glicério, com 14 prédios demolidos. Hoje [essas ruaș] são consideradas avenidas e [...] principais artérias do centro" (RELATÓRIO MUNICIPAL DE 1956 - SECRETARIA DE OBRAS E SERVIÇOS PÚBLICOS). 


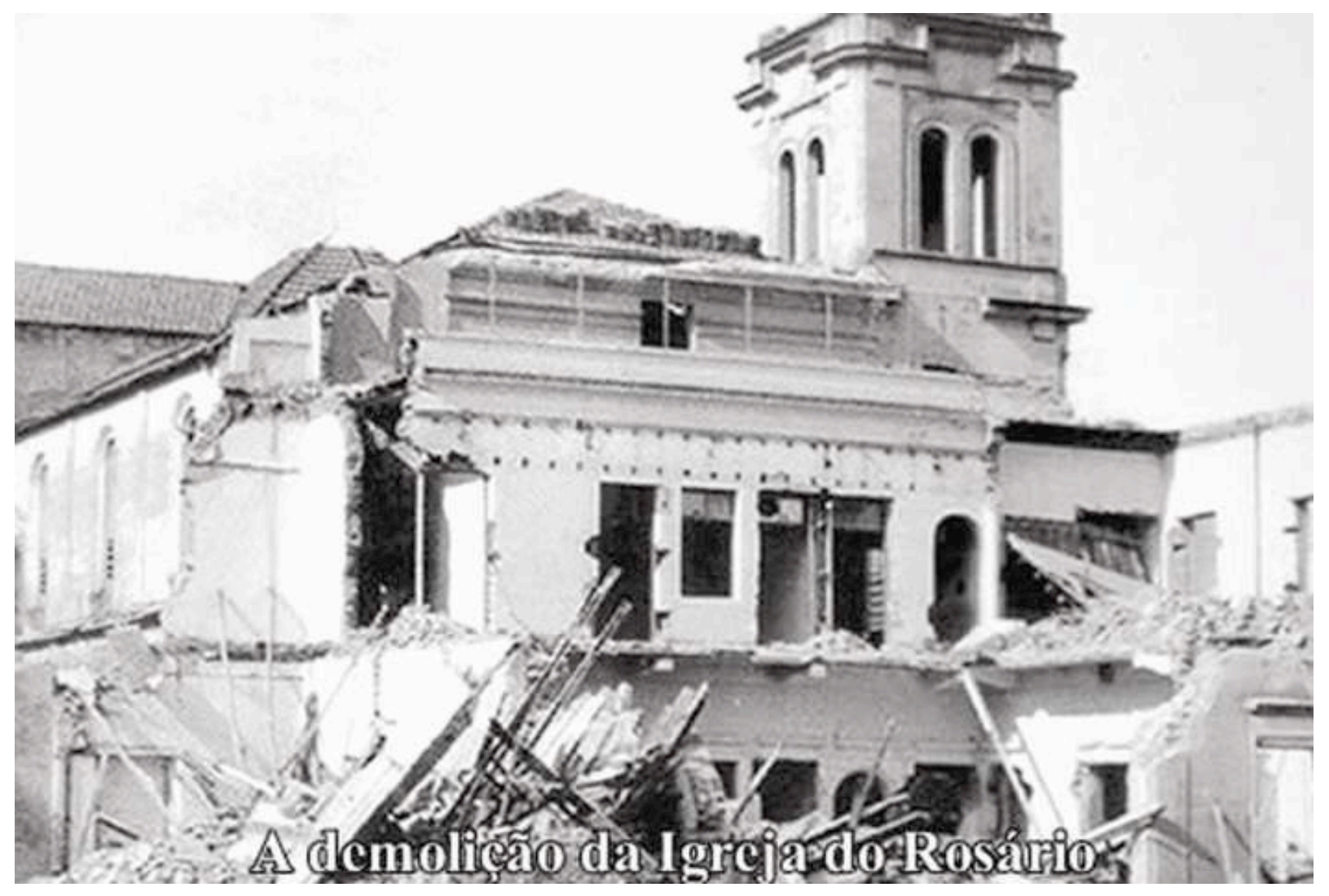

Figura 3 Demolição da Igreja do Rosário 1956.

Fonte: Acervo do Museu da Imagem e do Som (MIS).

A construção do Viaduto Cury, no lugar de uma antiga praça que ali existia, também é muito emblemática das transformações no desenho urbano e, mormente, no sistema viário, propostas pelo Plano de Melhoramentos Urbanos.

A importância dessa obra se associa também com a crescente influência do capital do setor de transportes nas decisões políticas, visto que a interligação viária da região da Vila Industrial (segregada historicamente do restante da malha urbana pela barreira física da ferrovia) era imprescindível para a expansão do serviço de transporte rodoviário intraurbano, cuja demanda já era expressiva, em virtude da abertura de novos loteamentos na direção sudoeste do município.

Ao mesmo tempo, essa e outras obras de infraestrutura eram consideradas imprescindíveis para dar a Campinas ares de grande centro urbano, mas sem perder a elegância planejada de um conjunto estético, funcional e uniforme, como se pode depreender da leitura de um trecho, reproduzido abaixo, da correspondência trocada entre membros da Comissão de Planejamento do Município:

[...] a C.P.M. [Comissão de Planejamento do Município] resolveu recomendar proceda V. Exa. imediatamente às necessárias 
desapropriações do trecho compreendido entre a avenida Francisco Glicério e o atual "Viaduto da Paulista" [...] obras reputadas imprescindíveis, aliás, pela Lei no 640, de 28 de dezembro de 1951, que aprovou a revisão do Ato 118, de 23 de abril de 1938, que 'dispõe sobre o plano de melhoramentos urbanos da cidade'.

A C.P.M. ainda, no intuito de acelerar a construção do viaduto e da praça, que existirá em frente ao mesmo, lembra [...] a oportunidade de ser [...] contratado um arquiteto urbanista [...] para projetar tais obras [...] inclusive a composição urbanística definitiva da Praça Marechal Floriano e da entrada oficial da cidade [...] tudo de molde a formar um conjunto harmônico, funcional, estético, uniforme e atraente (FUNDO DR. RUYRILLO DE MAGALHÃES, 1956) $)^{6}$.

Nesse sentido, pode-se observar que, na década de 1960, a velocidade da expansão urbana que se processara desde o início da década de 1930 havia produzido o precoce envelhecimento do Plano de Prestes Maia, que já não era mais capaz de responder à complexidade e à escala dos processos sociais e urbanos que se produziam na cidade.

No tocante a esse aspecto, durante um longo período, Campinas esteve órfã de legislação urbanística que efetivamente atualizasse os dispositivos de controle sobre a produção social do espaço.

Como bem lembrara o Diretor de Obras e Viação, no Relatório Municipal de 1954, a revogação parcial da lei no 640, que entre outros instrumentos estabelecia gabarito de altura para a zona central, permitiu ao capital imobiliário a incorporação de uma riqueza não tributada, de modo que este, sem grandes freios no que tange aos limites do direito de construir (maximizado pela obtenção de elevados coeficientes de aproveitamento), induziu a uma valorização diferencial da propriedade no centro da cidade.

Entretanto, os custos de produção da renovação urbana do centro de Campinas foram pagos por toda a cidade, na forma de impostos que financiaram a implantação de toda uma cara infraestrutura exigida pela verticalização, mas que não foi usufruída pela população trabalhadora expulsa para as áreas mais longínquas.

É importante sublinhar que a implantação do Plano de Melhoramentos Urbanos de Campinas, entre o final dos anos 1930 e a década de 1960 se assentou na umbilical relação historicamente construída entre o Poder Público e o capital

\footnotetext{
6 Memo de 20/12/1956, expedido pelo presidente da Comissão de Planejamento do Município e endereçado ao Prefeito Municipal. In: Acervo do Arquivo Municipal de Campinas, 2007. Fundo Dr. Ruyrillo de Magalhães, Caixa no 03, doc. 21 . Essa documentação, depositada no acervo do Arquivo Municipal de Campinas e somente disponibilizada recentemente à consulta pública é inédita
} 
gerado na distensão do complexo cafeeiro (reconhecido no trinômio capital industrial, imobiliário e de transportes), amplamente beneficiado por um projeto construído pelo e para os grupos econômicos e políticos dominantes, mas que se revestiu, ideologicamente, no imaginário social, como uma aspiração coletiva de progresso, desenvolvimento e modernidade, capazes de alçar Campinas à condição de grande centro urbano.

Nesse processo de renovação urbana, especialmente do centro, as profundas transformações na morfologia urbana de Campinas foram engendradas pela implantação de um programa urbanístico calcado no Plano de Prestes Maia, muito embora, evidentemente, sujeito às interpretações que convinham aos grupos dominantes que se revezavam no poder.

Isso significa dizer que a liberalidade com que o Poder Público tratou a atuação desse trinômio (capital imobiliário, de transportes e industrial) produziu pesados ônus sobre os gastos públicos, de modo que paulatina e crescentemente, as demandas sociais foram preteridas na agenda das políticas públicas, o que acabou por aprofundar ainda mais os fenômenos da segregação socioespacial e das desigualdades de renda e de acesso à cidade, aos seus bens materiais e simbólicos.

O aumento da densidade populacional em algumas regiões e a elevação da demanda de água provocada pelo abastecimento a empresas [...] fizeram com que já em 1964 fosse necessário retomar os investimentos em captação e distribuição [...] reflexo do 'desordenamento' urbano e ocupação de extensas áreas. [...] Portanto, não foi o crescimento demográfico em si que provocou a rápida saturação do abastecimento, mas o crescimento comandado pelos capitais imobiliários (ZIMMERMANN, 1989 , p. 127).

Desse modo, quando a incapacidade do Poder Público de responder às demandas legítimas das camadas populares se tornou indisfarçável, os grupos dominantes se reorganizaram para manter a defesa de seus interesses, ainda que ao custo de alguma regulação mais incisiva, como a que se fez através da nova legislação urbanística municipal, forçada pelas alterações no parcelamento, uso e ocupação do solo introduzidas pela lei 6.766/79 (ROLNIK, 1999).

Entretanto, deve-se salientar, a responsabilidade pela falência da máquina pública (CANO, 2003) não é reconhecida como decorrente de um programa de desenvolvimento econômico e urbano pautado nos interesses privados, mas sim é imputada aos pobres e às suas inadequadas áreas de moradia, bem como aos migrantes e às suas demandas sociais "impertinentes" aos interesses e 
disponibilidades das políticas públicas municipais.

Dito de outro modo, no apagar das luzes do Plano de Melhoramentos Urbanos, no final dos anos 1960, a reputação do planejamento urbano - e o próprio prestígio de Prestes Maia - são postos a salvo porque se consolidou no imaginário social a ideia perversa e equivocada de que, à revelia do planejamento urbano e de sua capacidade de "inventar" uma cidade rica, próspera e moderna para os campineiros, as massas de migrantes oriundas do interior do Estado de São Paulo, de Minas Gerais, Paraná e Bahia que acorreram à cidade no encalço da urbanização brasileira, tornaram, abruptamente, a promissora "cidade-modelo" uma verdadeira "cidade-problema".

\section{Referências}

BADARÓ, Ricardo de S.C. O plano de melhoramentos urbanos de Campinas (1934-1962). São Carlos, 1986. 276f. Dissertação (Mestrado em Engenharia Urbana) - Escola de Engenharia de São Carlos, Universidade de São Paulo. BAENINGER, Rosana. Espaço e tempo em Campinas: migrantes e a expansão do pólo industrial paulista. Campinas: CMU/Unicamp, 1996.

BAENINGER, Rosana; RODRIGUES, Fabíola. Diagnóstico sociodemográfico de Campinas: subsídio à revisão do Plano Diretor. In: SEPLAMA/PMC. Plano Diretor de Campinas, 2006. Campinas, 2006.

BRANDÃO, Carlos Antônio. Território \& desenvolvimento: as múltiplas escalas entre o local e o global. Campinas: Editora da Unicamp, 2007.

CAMPINAS. Prefeitura Municipal de Campinas. Relatório Municipal (19301974).

(1930-1939).

Decretos, Leis, Actos e Resoluções do Município de Campinas

. Código de construções, 1934.

Plano de melhoramentos urbanos, 1938.

CANO, Wilson et al. Economia paulista: dinâmica socioeconômica entre 1980 e2005. São Paulo: Alínea, 2007.

. Da crise ao caos urbano. In: GONÇALVES, Maria Flora; BRANDÃo, Carlos Antônio; GALVÃO, Antônio Carlos. Regiões e cidades, cidades nas regiões: o desafio urbano-regional. São Paulo: UNESP/ANPUR, 2003. CARPINTERO, Antonio Carlos Cabral. Momento de ruptura: as transformações no Centro de Campinas na década dos cinqüenta. Campinas: Editora da Unicamp, 1996.

FUNDAÇÃO SEADE. A interiorização do desenvolvimento econômico no 
Estado de São Paulo (1920-1980). São Paulo, 1988. (Coleção EconomiaPaulista, v.I, n.2).

FUNDO DR. RUYRILLO DE MAGALHÃES. Acervodo Arquivo Municipal de Campinas, 2007.

MAIA, Francisco Prestes. Rascunho de exposição preliminar. In: CAMPINAS.

Prefeitura Municipal de Campinas. Relatório Municipal de 1935. Campinas,1936.

NEGRI, Barjas. Concentração e desconcentração industrial em São Paulo (1880-1990). Campinas: Editora da Unicamp, 1996.

RIBEIRO, Daisy Serra. Campinas no Estado Novo: política de habitação popular na formação da cidade industrial. Campinas, 2007. 192f. Tese (Doutorado em História) - Instituto de Filosofia e Ciências Humanas, Universidade Estadual de Campinas.

RODRIGUES, Fabíola. A Invenção da Cidade: população e planejamento urbano, imaginário e poder na formação urbana de Campinas (1930-2006). Campinas, 2008. 363f. Tese (Doutorado em Demografia) - Instituto de Filosofia e Ciências Humanas, Universidade Estadual de Campinas.

ROLNIK, Raquel. A cidade e a lei: legislação, política urbana e território nacidade de São Paulo. São Paulo: Studio Nobel, 1999.

SEMEGHINI, Ulysses. Do café à indústria: uma cidade e seu tempo. Campinas: Editora da Unicamp, 1991.

ZIMMERMANN, Gustavo. O município no sistema tributário: os municípios paulistas e o caso de Campinas (1986). In: FUNDAÇÃO SEADE. A interiorização do desenvolvimento econômico no Estado de São Paulo (1920-1980). São Paulo, 1989. (Coleção Economia Paulista, v.I, n.3).

; SEMEGHINI, Ulysses. Explosão urbana regional e

demandas sociais no Estado de São Paulo 1970-1985. Campinas: IE/FECAMP/Secretaria de Economia e Planejamento do Estado de São Paulo, 1988. (Relatório Final, v.II - Estudos de Caso, Campinas). 